\title{
THEORETICAL APPROACHES TO ASSESS EFFICIENCY OF THE TRANSFORMATION OF THE KEY BUSINESS PROCESSES IN THE PUBLISHING AND PRINTING ACTIVITIES IN THE REGION
}

\author{
Volodymyr BAZYLIUK' \\ Ukrainian Academy of Printing, Ukraine
}

\begin{abstract}
The purpose of the paper is the theoretical study and the analysis of the basic methodological approaches to assess the effectiveness of the transformation of key business processes in the PPA (publishing and printing activity) in the region in order to choose the best option. Methodology. The overview of the main assessment methods of the effectiveness of business processes: EVA (Economic value added); ABC (Activity-based costing); Tableau of bord and BSC (Balanced Scorecard) is provided. In order to ensure the formalization of the intergrated assessment of the effectiveness of the business process in the publishing and printing activities in the region it is suggested to apply to the methodological apparatus of the fuzzy sets. Statistical analysis, comparison and synthesis are necessary to study the efficiency of the transformation of the key business processes in the PPA in the region. Results. The review and analysis of the most common methods for evaluating the effectiveness of the transformation of key business processes were conducted; the basic advantages and disadvantages of each of the proposed methods in the light of PPA were studied. It was proved that a single business process involves the use of a scorecard that is specific and peculiar for it only whereas completeness of its analysis depends on the kind of the business process: basic, developmental, managing or providing one. The approach to the formalization of the integrated assememnt of the effectiveness of business process in PPA in the region, based on the theory of fuzzy sets was formulated. Practical significance. The mathematical formulation of the problem, an integrated assessment of the efficiency of the business process for each of the possible options for its implementation was developed, and the algorithm of assessing the effectiveness of the business process in the PPA in the region was generated by the apparatus of fuzzy sets. Value/originality. Implementing the proposed approach allows to formalize and numerically evaluate the effectiveness of each of the options of the transformed business processes.
\end{abstract}

Key words: business process, assessment, efficiency, publishing and printing activity, region.

JEL Classification: O11, L82, R10

\section{Introduction}

Problems of the quantitative assessment of the effectiveness of a certain business process, that is the local criterion of its adaptation to institutional changes have not been finally solved in the scientific literature. Therefore, the main area in solving this problem is to analyze the theoretical and methodological approaches to the identification and the development of the modern tools for evaluating the effectiveness of the business process.

To determine the feasibility of transforming a certain business process in the PPA in the region as well as to select one of the possible options for these changes, an approach that would give an opportunity to evaluate its effectiveness quantitatively is required. The summary of the gained experience in the design and applying the approaches to the quantitative assessment of the level of business process efficiency indicates that no common methodology is present nowadays as not only a list of performance but also the methods of their quantitative measurement indicators vary.

\section{Methods of assessing the effectiveness of business processes}

Before conducting an analysis of the current approaches to evaluation it is noteworthy to underscore the essence of the business processes transformation, which is a set of measures aimed at optimizing, that is, improvement of efficiency, productivity and competitiveness of the existing business processes and ensuring the general sustainable development of PPA in the region. The feasibility of the assumptions made by us is also proved in the papers of other researchers who point out that the purpose of improving the efficiency

Corresponding author:

${ }^{1}$ Department of Enterprise Economics and Marketing in Military Industrial Complex, Ukrainian Academy of Printing.

E-mail: bvb.uad@ukr.net 
of business processes is improving the functioning of a system of business processes in the business entities and, consequently, improvement of their competitiveness and strategic development, (Harrington, Esseling \& van Nimvegen, 1997). However, this approach is quite limited as we find that it does not take into account such important aspects as time and technical aspects.

There is a number of methods for evaluating the effectiveness of business processes, which are widely used in the world. We consider that the following ones should be paid special attention at: EVA (Economic value added); methods of cost analysis of business processes ABC (Activity-based costing); Tableau of bord methodology and the balanced system of indicators BSC (Balanced Scorecard).

We study the pecualirities of applying each of them. Thus, the EVA methodology focuses on the fact that all business processes can be divided into two components: the first one adds the value for the product cost, and the second one does not increase its use value, (Mäkeläinen \& Roztocki, 1998). It is adding value by the business process that is generally used as the main incentive for its implementation.

In correspondence with the presented approach, there is an assessment of the business process that adds value by means of a specific indicator, defined by the ratio of market value and incurred costs of producing goods. However, under such circumstances, the proposed method is effective for the assessment of key business processes and development processes only, and applying this approach for the evaluation of providing business processes in PPA in the region that do not relate to the processes which add value directly is impractical.

Another widely-spread method of evaluating the efficiency of business processes is a method of cost analysis of the $\mathrm{ABC}$ processes, which includes planning and calculation of the cost of a business process based on the definition and preparation of the costs for activities that ensures this process, (Kaplan \& Cooper, 1997). $\mathrm{ABC}$ method is an effective way to evaluate the use of resources and processes and can be used separately from the comprehensive assessment of qualitative and quantitative indicators.

However, a significant drawback of this approach is that the process is usually implemented in several different units, so that gaining information on the spent income and the resources for each of them is a complicated task.

The next method that is considered by us is Tableau of bord, which is one of the oldest integrated methods of managing the efficiency of the complex socioeconomic systems and is based on the approach of building a hierarchical tree of indexes through their decomposition, (Epstein \& Manzoni, 1997).

The main advantage of this method lies in the possibility of forming a tree of target and functional indexes. Thus, target indexes are primatily applied at the upper levels of the tree, and functional ones are used at the lower and middle ones.

Despite the advantages of the possibility of the evaluation of business processes at every level of the complex socio-economic system and the formation of various groups and flexible performance, this technique has some drawbacks, namely, difficulties in ensuring a certain equilibrium in the system parameters.

This problem could be partly solved by BSC, another well known and more frequently used technique, formulated by D. Norton and R. Kaplan, (Kaplan \& Norton, 1996). The main principal feature of BSC compared to other approaches was the division of the entity activity in four areas: finance; customers; internal processes and staff.

However, due to the peculiarities of PPA in the region there is complexity for the application of this technique to evaluate the effectiveness of business processes. It is primarily predetermined by the complexity of assessing such direction as customer efficiency. Therefore, a part of subjects of PPA in the region is engaged in the implementation of the business process associated with the production and sale of packaging and labels, whereas the consumers of such products is mainly processing industry. Under such conditions, the relationship between producers and consumers of products are usually long-term, and the change in product sales channel is rare. In its turn, it will lead to the fact that client assessment will be based on an analysis of a small number of consumer labels and packaging and, accordingly, its outcomes can not find out the noneffective business processes as a result of the analysis.

Nowadays, the methodology for assessing the efficiency of business processes formed to determine the key performance indicators is widespread. Therefore, in this area, one of the most common evaluation techniques of a business process is KPI (Key Performance Indicator), which consists of a set of indicators that help to determine the degree of success as a result of the business process implementation or the level of achieving its objectives. In correspondence with this technique, the approach to lean production lies in the basis of ranking business processes, (Oliver, Delbridge \& Barton, 2002), and the efficiency of business processes is evaluated according to four criteria: the degree of completeness of customer service (speed of business process, content of the work on its implementation, etc.); performance of the business process; the cost of the business process; quality of the business process.

\section{The system of indicators to measure the efficiency of business processes}

Experience as well as represented approaches show that effective assessment of the business process can be ensured only on the basis of a system of indicators; 
we believe that it should consist of a set of indicators that will provide a comprehensive and complete characterization of the analyzed business process in PPA in the region. In this case, this assessment will be local, because its function is analyzing activities under a single business process.

We consider that every single business process involves the use of a scorecard that is specific and peculiar to it only, and completeness of its analysis depends on the type of a business process: basic, developmental, managing and providing one.

Therefore, we believe that the system of indicators to measure the efficiency of transformation as a basic business process, and its lower levels of the hierarchy should be as much complete as possible. However, regardless of the specific assessment of each of the effectiveness of the business process under consideration, and efficiency criteria should be the basis of a local assessment system for absolutely all business processes.

Consequenly, within the quantitative indicators of business processes efficiency, the use of the following indicators is suggested to be taken into account in the regional PPA:

- cost indicator, which means that figures show the value of the cost of resources used in the business process and profit earned on the sales of products that are manufactured in this process, (Spieß, Nguyen, Weber, Markovic \& Beigl, 2008). Indicators of this group are considered to be the most important because they directly reflect the efficiency of business processes in the terms of value. The abovementioned $A B C$ method became widespread in the analysis of cost indexes. As a rule, under the application of the method, the following indicators are applied: the amount of the resources needed for the process; resources received by the output process (ready-made products) and the value of resources used for the specific functions of the process. We find that a large number of resulting indicators for each group determines inconsistency in determining the importance of an indicator in comparison with others that has a negative impact on quality assessment. Thus, for the purpose of the formation of an effective evaluation system of the PPA business processes in the region, we consider the combination of indicators noteworthy. Therefore, the cost evaluation of the business process can be carried out based on the index, which is calculated by the ratio of the output in the specific business process to the resource costs incurred in its implementation;

- technical indicator includes indexes that characterize the equipment and technologies used in the implementation of a business process. Technical parameters serve as a basis for the formation of specific technical indicators to assess business process (eg, production per worker, the degree of automation of the process and the cost of using new technologies, etc.).
It should be notified that because of the technological features, different groups of indicators that meet the requirements of the current analysis of the business process effectiveness can be formed. So, given the outlined promising areas of business transformation process of production and sales in the PPA in the region, it was found out that under the changes in the institutional environment, considerable interest to change lies in the technological plane (the use of new types of printing (digital, electrographic types and significant impact on the development of information technology). Taking it into consideration, we believe that since the assessment of the business process of production and marketing is carried out, the indicator that would combine the implementation of publishing and printing products and the costs of implementing new technologies should be applied. Therefore, this indicator is proposed to be calculated by the ratio of sales (both the one that was produced by means of new technology and equipment and the one that was sold in e-commerce) to the cost of implementing new techniques and technologies;

- time indicators that show time efficiency in the business process, reveal the odd functions of the process and determine the downtime. In order to analyze the performance of the proposed system it is necessary to form a system of time tracking as performance of each business process must be regulated and compared with the established norms. It should be noted that for PPA and business process in the production and sale of publishing and printing products, in particular, a system of norms and standards for the regulation of this process is valid, and a significant reserve for improving the efficiency of production is the reduction based on the application of innovative approaches of working time (including unproductive one) and reducing the time of the cycle of production and sales. Thus, the measure, which would assess the effectiveness of the business process in the time aspect is the time of the cycle of production and the sales of publishing and printing products.

As a rule, in a variety of valuation techniques of different economic phenomena, quantitative indicators are applied because the qualitative ones are not considered accurate and are largely subjective, so that they receive less attention. However, W. Deming argued that managing an economic entity only on the basis of actual figures without paying enough attention to quality indicators that are not measurable means catching a "deadly disease" of management, (Deming, 2007). Therefore, we believe that a balanced system of evaluating the effectiveness of business process in PPA in the region, qualitative indicators should be taken into account along with the quantitative ones. Besides the abovementioned quantitative indicators, we propose to consider taking into account the following quality indicators in the methodology:

- the quality of the process, that is, meeting the production requirements of customers; it reflects the 
level of conformity of the product and the reference product with market expectations. Thus, we consider process quality as the property of products obtained through the implementation of business process to meet customer requirements, printing and publishing market;

- adaptability, a feature of the process to meet the future, constantly changing and specific customer requirements. We believe that this criterion should be viewed more broadly, taking into account not only consumers but also the entire operation of the PPA environment. At this point, the importance of this criterion in adapting PPA in the region to institutional changes is suggested. It is predetermined by the fact that it does not matter how much perfect the process is in terms of efficiency and prospects; if it can not adapt to the existing institutional framework, it undergoes further transformations and ceases to function in the previous form.

The basis of the proposed methodology for assessing the efficiency of business processes is the following: conceptual apparatus, performance evaluation, evaluation methods and algorithms for the calculation of performance based on design. Regarding the first two points, they are sufficiently developed in the scientific literature that makes us resolve the last two tasks, which are characterized by considerable uncertainty.

\section{Method of forecasting complex social and economic systems}

An effective tool for solving problems concerning the prediction of complex social and economic systems with a significant level of uncertainty is the theory of fuzzy sets, (Zadeh, 1965). In the dynamic environment, the theory of fuzzy sets is widely used to solve applied problems in the economy and suggests promising and appropriate use of fuzzy sets in solving some of the problems to assess the effectiveness of business processes.

In order to study the usefulness of this approach we cite the main tenets of the theory of fuzzy sets. Suppose that $\mathrm{V}$ is a complete set that consists of a certain class of objects, and C is a fuzzy subset of the set of $\mathrm{V}$, which is calculated by the $n$ function

$$
C=\mu_{c}(T) \in[0,1]
$$

and displays all the elements $\mathrm{T}$ of the totality $\mathrm{C}$ on the set of real numbers of the interval $[0,1]$ that indicate the degree of affiliation of each element of the fuzzy sets (aggregate) $C$;

$\mathrm{C} \in \mathrm{V}, C=\left\{C_{j}\right\}-$ fuzzy assessment of the $j$-th object of study,

$$
\begin{aligned}
& C_{j}=\mu_{C_{j}}\left(T_{j}\right), \\
& C_{j}=\left\{\mu_{C_{j}}\left(T_{j i}\right) / T_{j i}\right\} .
\end{aligned}
$$

Evaluation of the functions that belong to the $j$-th criterion is based on the formula:

$$
C_{j}=\mu_{C_{j}}\left(T_{j}\right)=\mu_{C_{j}}\left(T_{j 1}\right) / T_{j 1} V \ldots V \mu_{C_{j}}\left(T_{j i}\right) / T_{j i} V \ldots V \mu_{C_{j}}\left(T_{j n}\right) / T_{j n},(4)
$$

where $T_{j i}$ is the value of $j$-th local parameter of the estimation of the $i$-th variant of the business transformation process, and the symbol "/" means the property of belonging of the element that is after the symbol.

For the purpose of the proposed approach for the formalization of an integrated assessment of the efficiency of the business process in the PPA in the

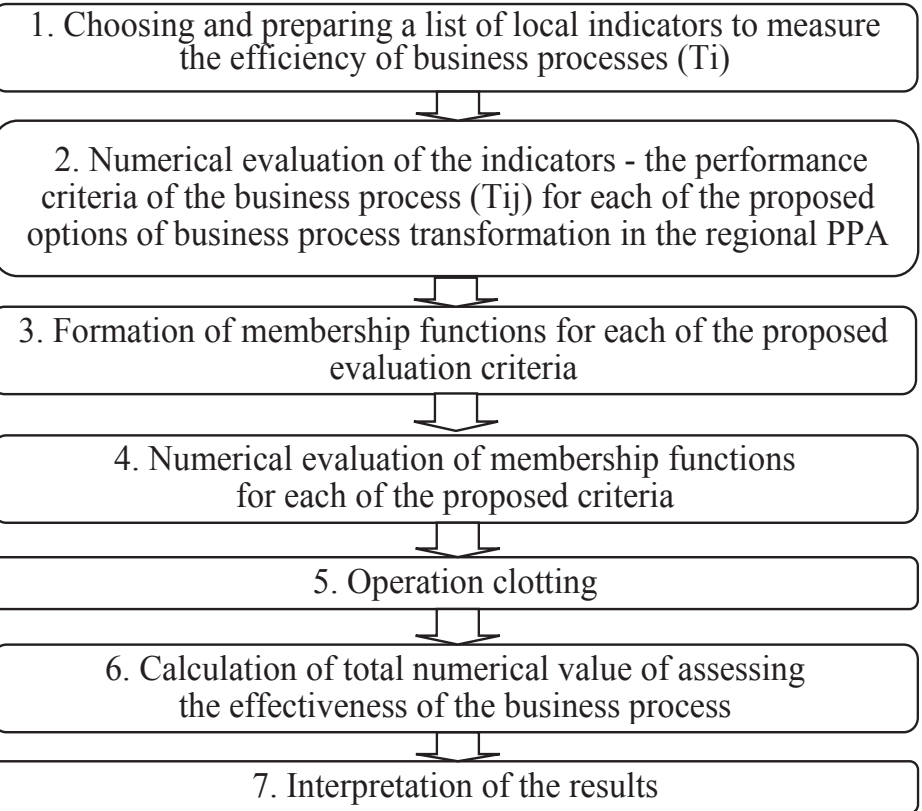

Fig. 1. Algorithm for evaluating the effectiveness of business process in the regional PPA based on the fuzzy sets 
region we propose a mathematical formulation of the problem, an integrated assessment of the efficiency of the business process for each of the possible options for its implementation.

Assume the existence of a number of options for implementing business process and a list of evaluation criteria. Thus, the evaluation criteria are local (qualitative and quantitative) indicators of the business processes efficiency that characterize some of the concepts and the assessment of alternatives is the degree of compliance with the concept. Estimates of the options of the business process for each $j$-th criteria are fuzzy sets $C_{i}$.

Then, folding rule will be the following:

$\mu_{D}\left(T_{i j}\right)=\min \mu_{C_{j}}\left(T_{i j}\right)$,

where $\mathrm{D}$ is the intersection of the fuzzy sets, which is calculated by the formula:

$$
D=C_{1} I C_{2} I T I C_{m} \text {. }
$$

$\mathrm{Bi}$ Index is calculated by the formula:

$$
B_{i}=\min \mu_{D_{j}}\left(T_{i j}\right) \text {. }
$$

Therefore, the implementation of the proposed approach allows to formalize and numerically evaluate the effectiveness of each of the options for the transformed business processes.

We find that the fulfillment of the set task is necessary to make the following algorithm (Fig. 1).

Another advantage of applying this approach is the possibility of modeling the situation development. In addition, on the basis of the conducted research and analysis on the articles by the leading experts on optimization and evaluation of business processes, the level of consistency of thoughts which was assessed and defined as very high, the parameters that characterize the main directions of efficiency, namely, cost, technical, time quality and adaptability must be selected from the totality. In future, in order to conduct a full assessment under the proposed areas on the basis of the parameters, it is necessary to form a system of performance evaluation that should be a subject of the further research.

\section{Conclusions}

The summary of the existing methods that are widely used in practice allows us to offer our own vision on such parameters as assessment as a modern tool of solving problems in assessing the efficiency of business processes; later, it will lay the basis for our proposed methodological approach.

The suggested system of evaluating the effectiveness of key business processes in the regional PPA should consist of two groups of indicators: quantitative indicators that include the quantities that can be measured directly and qualitative indicators, that is, the measurement that is ensured indirectly through peer reviews, which increases their subjectivity in most cases.

Thus, the presented approach to the application of fuzzy set theory to formalize an integrated assessment of the efficiency of the business process in the regional PPA and formed mathematical formulation of the problem, an integrated assessment of the efficiency of business process allows us to conduct this assessment and choose the best option from the set of represented variants of transformation.

\section{References}

Deming, U. E. (2007). Novaya paradigma upravleniya lyudmi, sistemami i protsessami - Moscow, Alpina Business Books, $370 \mathrm{p}$.

Epstein, M. J. \& Manzoni, J.-F. (1997). The Balanced Scorecard and Tableau de Bord: Translating Strategy into Action. Management Accounting, Vol. LXXIX, No. 2, p. 28-36.

Harrington, J., Esseling, E., van Nimvegen, H. (1997). Business Process Improvement Workbook: Documentation, Analysis, Design and Management of Business Process Improvement - New York, McGraw-Hill Publishing, 314 p. Kaplan, R. S. \& Norton, D.P. (1996). The Balanced Scorecard: Translating Strategy into Action - Boston, HBS Press, 269 p.

Kaplan, R.S. \& Cooper, R. (1997). Cost and Effect: Using Integrated Cost Systems to Drive Profitability and Performance - Harvard Business School Press, 357 p.

Mäkeläinen, E. \& Roztocki, N. (1998). Economic Value Added (EVA) for small business. Retrieved from: http://www.evanomics.com/download/evaspres.pdf

Oliver, N., Delbridge, R., and Barton, H. (2002). Lean production and Manufacturing performance improvement in Japan, the UK and US 1994-2001. ESRC Centre for Business. Retrieved from: www.netec.mcc.ac.uk/WoPEc/ data/Papers.

Spieß, P., Nguyen, D., Weber, I., Markovic, I. \& Beigl, M. (2008). Modelling, Simulation, and Performance Analysis of Business Processes Involving Ubiquitous Systems. CAiSE, p. 579-582.

Zadeh, L.A. (1965). Fuzzy sets. Information and Control, V. 8, p. 338-353. 


\section{Владимир БАЗИЛЮК}

ТЕОРЕТИЧЕСКИЕ ПОДХОДЫ К ОЦЕНКЕ ЭФФЕКТИВНОСТИ ТРАНСФОРМАЦИИ КЛЮЧЕВЫХ БИЗНЕС-ПРОЦЕССОВ В ИЗДАТЕЛЬСКОЙ И ПОЛИГРАФИЧЕСКОЙ ДЕЯТЕЛЬНОСТИ В РЕГИОНЕ

Аннотация. Целью работы является теоретическое обоснование и анализ основных методологических подходов к проведению оценки эффективности трансформации основных бизнес-процессов ИПд (издательско-полиграфической деятельности) в регионе с целью выбора наиболее оптимального варианта. Методология. Проведен обзор основных методик оценки эффективности бизнес-процессов: EVA (Economic value added) ABC (Activity-based costing) Tableau of bord и BSC (Balanced Scorecard). С целью формализации интегрированной оценки эффективности бизнес-процесса издательско-полиграфической деятельности в регионе предложен методологический аппарат теории нечетких множеств. Статистический анализ, сравнение и обобщение - для изучения эффективности проведения трансформации бизнес-процессов ИПД в регионе. Результаты. Обобщены наиболее распространенные методики оценки эффективности трансформации основных бизнес-процессов, рассмотрены основные преимущества и недостатки применения каждой из предлагаемых методик через призму ИПД. Доказано, что отдельный бизнес-процесс предусматривает применение специфической и присущей только ему системы показателей, а полнота его анализа будет зависеть от того, к какому виду относится бизнес-процесс: основной, развития, управления или обеспечивающий. Сформирован подход формализации интегрированной оценки эффективности бизнеспроцесса ИПД в регионе, основанный на теории нечетких множеств. Практическое значение. Осуществлена математическая постановка задачи - интегрированной оценки эффективности бизнес-процесса для каждого из возможных вариантов его реализации и разработан алгоритм оценки эффективности бизнес-процесса ИПД в регионе на основе применения аппарата теории нечетких множеств. Значение/оригинальность. Реализация предложенного подхода позволяет формализовать и численно оценить эффективность каждого из вариантов бизнес-процессов что трансформировались. 